\title{
OSMANLI TIP METİNLERİNDE GEÇEN CERRAHÎ ALET ADLARI ÜZERINE
}

\author{
On the Names of Surgical Devices in Ottoman Medical Science Text
}

\section{Mehmet GÜRLEK ${ }^{1}$}

\section{ÖZET}

14. yüzyılın ikinci yarısından itibaren Osmanlı sahasında Türk dili ile yazılan eserlerin arttığını görmekteyiz. Bu eserler içinde tıp alanında yazılanlar sadece dil çalışmaları için değil botanikten halk hekimliğine, farmakolojiden tıp tarihine kadar bilim tarihimiz için büyük önem arz eder. Bu çalışmada Osmanlı sahasında yazılmış ilk Türkçe cerrahî tıp yazmalarında geçen cerrahî alet adları üzerinde durulacaktır. Çalışmanın veri tabanını 15. Yüzyıl ile 16. yüzyılın başında yazılmış olan Cerrâhiyyetü'lHâniyye (Müellifi Sabuncuoğlu Şerafeddin), Kitâb-ı Hulâsa-i Tıbb (Müellifi Cerrah Mesud), Alaim-i Cerrâhin (Müellifi İbrahim bin Abdulah) ve Anonim Cerrah-nâme isimli eserler oluşturacaktır. Çalışmada bu eserlerin en iyi nüshaları esas alınmış alet adlarının geçtiği varak ve satır numaraları verilmiş ve metinden örnek cümleler çevriyazı ile aktarılmıştır.

Anahtar Kelimeler: Cerrahî alet adları, tıp tarihi, tıp terimleri, Osmanlı tıbbı.

\section{ABSTRACT}

From the second half of the 14th century onwards, it has been observed that in the Ottoman period, works written in Ottoman Turkish (otk) have significantly increased in number. Among these works which focus on medical science, some are of great importance, not only in terms of linguistic studies, but also in terms of a number of other disciplines ranging from history of science to botany, public medicine to pharmacology, and to history of medicine. This work demonstrates a concept-based list of names of surgical devices which can be traced back to early works on general surgery written in Ottoman Turkish (otk/ota) during the Ottoman period. Works such as Cerrahiyyetü'l-Haniyye (by Sabuncuoğlu Şerafeddin), Kitab-1 Hülasa-i Tibb (by Cerrah Mesud), Alaim-i Cerrahin (by İbrahim bin Abdulah ) and Anonym Cerrah-name, which were written in the 15th century and the early 16th century, will set up the basis of our data base. This article comprises the best available prints of these works which are selected for examination; page numbers and related lines of surgical devices have been specified and, moreover, exemplary sentences have been obtained from these original texts by transcription, and will be presented in the article.

Key words: Names of surgical devices, history of medicine, medical terms, Ottoman medical science.

\section{GíRIS}

Anadolu Selçukluları döneminden kalma Mardin Emînüddîn Mâristânı (1108-1122 arası), Kayseri Gevher Nesibe Tip Medresesi ve Mâristânı (1206), Divriği Turan Melek Dârüşşifâsi (1228), Kastamonu Ali bin Süleyman Dârüşşifası (1272), Amasya Dârüşşifası (1220-1237) gibi tıbbî kurumlar ${ }^{2}$ tıp biliminin Türkler arasında geliştiğinin bir göstergesidir. Ancak bu dönemden kalma Türkçe yazılı metinlerin azlığı sebebiyle bu gelişmenin derecesini tam olarak belirlemek güçtür. T1bbî kurumlar Osmanlı döneminde çok daha gelişmiştir. Bursa Yıldırım Darüşşifası (1400), Fatih Darüşşifası (1470), Osmanlı Cüzzamhâneleri ve Üsküdar Miskinler Tekkesi (1514), Haseki Dârüşşifası (1550), Süleymaniye Dârüşşifası ve Tip Medresesi (1559), Atik Valide Dârüşşifası (1582) ilk akla gelenlerdir.

Osmanlı döneminde yazılan tıp konulu metinler -her ne kadar kronolojik olarak sıralamak güç olsa da- oldukça çoktur. Bu dönemden kalan müellifi bilinen ilk tıp metinleri Geredeli İshak bin Murad'ın yazdığı Edviye-i Müfrede (Canpolat, 1973: 21) ile Hekim Bereket'in Tuhfe-i

\footnotetext{
${ }^{1}$ Yrd. Doç. Dr., İstanbul Üniversitesi, Edebiyat Fakültesi, Dilbilimi Bölümü, Mail: mehmetgurlek@gmail.com

2 Selçuklu ve Osmanlı Döneminden kalma Şifahaneler için Bkz. Anadolu Selçuklu ve Osmanlı Şefkat Abideleri Şifahaneler (Haz. Abdullah Kılıç), İstanbul-2012.
} 
Mübârizî̉ dir (Bayram, 1995: 95-100). Ağırlıklı olarak farmakolojik ve koruyucu hekimlik özellikleri gösteren Terceme-i Müfredât-1 İbni Baytar, Kâmilü's-Sınâa Tercümesi, Müntahab-1 Şifâ, Teshîlü'ş-şifâ, Tervîhü'l-ervâh, Tuhfe-i Mübârizî, Yâdigâr, Hazâinü's-saâde, Akrabadin Tercümesi gibi eserlere baktığımızda Selçuklular döneminde ihmal edilen Türkçenin artık bir bilim dili olduğunu söyleyebiliriz. Ayrıca Cevat İzgi Osmanlı Medreselerinde İlim adlı çalışmasında (1997: 42) Osmanlılar döneminde yazılan tıbbî eserlerin yaklaşık yüzde yetmiş ile sekseninin Türkçe olarak yazıldığını ifade etmektedir.

Cerrahî konulardan bahseden kitaplara Cerrahnâme adı verilir. Cerrahnâmeler, diğer tıp yazmaları gibi ait oldukları dönemlerin cerrahî uygulamalarını içeren ve bunların günümüze de ulaşmalarını sağlayan önemli belgelerdir (Acıduman vd. 2008:5). Osmanlı sahasında Cerrâhiyyetü'l-Hâniyye, Kitâb-ı Hulâsa-i Tıbb, Alâim-i Cerrâhin ile Anonim Cerrâh-nâme ilk cerrahî tıp kitapları arasında yer almaktadır.

Cerrâhiyyetü'1-Hâniyye³ : Anadolu sahasında yazılmış en önemli cerrahî tıp kitabıdır. 1465 yılında Fatih Sultan Mehmed'e sunulmuştur. Sabuncuoğlu Şerafeddin tarafindan yazılan eser ünlü hekim Ebü'l-Kâsım ez-Zehrâvî'nin et-Tasrîf adlı eserin çevirisi olmakla birlikte Sabuncuoğlu'nun tecrübelerine de yer verir. Eserin değerini artıran bölümler ise tedaviler ile cerrahî alet çizimlerine yer vermesidir. Eserin metni ve tıpkıbasımı İlter Uzel tarafından yayımlanmıştır (Uzel 1992). Anonim Cerrâh-nâme ${ }^{4}: 16$. Yüzyılın başında yazılmış bir diğer cerrahî tıp yazması da yazarı bilinmeyen Cerrah-nâme'dir. Bu eserdeki cerrahî bölümlerde cerrahî aletler bulunmakla birlikte ne yazık ki minyatür ya da çizim yer almamaktadır. Eser üzerinde Serdar Yavuz çalışma yapmıştır (Yavuz 2013). Kitâb-1 Hulâsa-i Tıbb ${ }^{5}$ : Hulâsa adıyla da bilinir. Cerrah Mesud tarafindan yazılmıştır. Otuz bölümden ibarettir. Bu eserde de herhangi bir çizim yoktur. Eser üzerinde İlhan Uçar'ın doktora çalışması bulunmaktadır (Uçar 2009). Alâim-i Cerrâhin ${ }^{6} 1505$ tarihinde yazılmış ilk Türkçe cerrahî yazmalar arasında yer almaktadır. Eserin müellifi İbrahim bin Abdullah olup ateşli silahlarla yaralanmalara ve frengi hastalığına ilk defa yer veren eser olarak bilinmektedir. Eser üzerine tarafımızdan doktora çalışması yapılmıştır (Gürlek 2011).

Cerrahî, diğer tıp konularına nisbetle daha yavaş bir gelişim çizgisi izlemiştir. Her ne kadar cerrahî uygulamaları arasında kabul edilen kırık çıkık tatbikatları ve bazı basit yara tedavilerine çok erken tarihlerden itibaren rastlanmaktaysa da, konuyla ilgili gelişmelerin belli bir düzeyde ele alınması için, hatta bugünkü anlamda cerrahî için, ondokuzuncu yüzyılı beklemek gerekir. Genel olarak tıpta otorite olarak kabul edilen Hippokrates, Galen ve daha sonra İslâm Dünyasında Razî, Ali b. Abbas ve İbn Sînâ gibi hekimler, her ne kadar pek cerrahî ile ilgilenmemişlerse de, zaman zaman cerrahî tedaviye başvurmak zorunda kalmışlardır. Onların cesaretini kıran şüphesiz ki cerrahî tedavinin sonucunun daima başarılı olmaması, hatta ölüm riskinin yüksek olması olmuştur. Ameliyat sırasında temiz aletlerin kullanılması gerektiği, hastanın ameliyat sonrası bakımının çok önemli olduğu ve nasıl muamele edilmesi gerektiği üzerinde önemle durmuşlardır (Kahya 2013).

Prof. Dr. Nil Sarı TDV Íslam Ansiklopedisi için hazırladığı "Cerrahlık" maddesinde (cilt 7: 423) Osmanlı cerrahlığ 1 ile ilgili şu ifadelere yer vermiştir: "Cerrahlık Osmanlılar'da maharet ve tecrübe isteyen bir meslek dalı olarak görülürdü ve cerrah daha çok bir sanat erbabı sayılırdı. Bu sebeple cerrahlık mesleği, ya sarayda ehl-i hiref teşkilâtına bağgl olarak veya usta bir cerrahın yanında yahut babadan oğula geçen bir sanat şeklinde öğrenilirdi. Cerrahlar dârüşşifâlarda, saraylarda, orduda veya "dükkân" denilen muayenehanelerinde çalışırlardı. Yara ve çıban tedavisi,

\footnotetext{
${ }^{3}$ Nüshaları: Fatih Millet Küt. 79, İstanbul Üniversitesi Tıp Fak. Tıp Tar. Kürsüsü Küt. TY 263; Paris Bibliotheque National Turc 693.

${ }^{4}$ Nüshaları: İstanbul Arkeoloji Müzesi Küt. 729; Süleymaniye Küt. Yazma Bağışlar 814.

${ }^{5}$ Süleymaniye Küt. Fatih 3550, Süleymaniye Küt. İsmihan Sultan 332; Bursa Küt. Haraçcıoğlu 1149/1

${ }^{6}$ Süleymaniye Kütüphanesi, Hekimoğlu Ali Paşa, No. 568; Millet Kütüphanesi, Tıp, No. 205; İ. Ü. Cerrahpaşa Tıp Fakültesi, Tıp Tarihi ve Deontoloji Kürsüsü, Y.125; Wilhelm Pertsch: Die Türkische Handschriften der herzoglischen Bibliothek zu Gotha.Wien 1864, s. 94-95, No.107.; Manisa İl Halk Kütüphanesi, Eski eserler, No. 1844; Manisa İl Halk Kütüphanesi, Eski eserler, No.1851; İstanbul Üniversitesi Kütüphanesi, TY. 7147
} 
fitık rahatsızlıklarının iyileştirilmesi, diş çekimi, kan alma, sünnet gibi müdahaleler cerrahın meşgul olduğu başlıca işlerdi. Saray cerrahları ayrıca Enderun'a alınacak devşirmelerin ve hadım ağalarının muayenelerini de yaparlardı. Bunların âmirine sercerrâhîn-i hâssa veya cerrahbaşı denirdi. Ordu cerrahlığına saray cerrahlarının en yeteneklisi, dârüşşifâlara ise usta ve tecrübeli cerrahlar tayin edilirdi."

Eserlerini incelediğimiz cerrahlardan İbrahim bin Abdullah ve Cerrah Mesud eserlerinde büyük hekim Galen'in söylediğini iddia ettikleri şu sözler ilginçtir: "Her cerrāha vācib olan oldur ki evvel 'ilmi dürüst gerekdür, tā ki 'ameli rāst ola ve ba'dehū cerrāh olan kimesne şefkatlü ve güler yüzlü gerekdür ve dah̆ı üstād kavlince yüriye ve kendüyi alçak duta ve dah̆ı bāki üstāzlları yermeye. Ve dahı Cālinūs buyurur kim: Bu cerrāḥlık didükleri nesne münakkaş evlere beñzer ve bir ma'nāda deryā-yı 'ummāndur ucı ve kıyāsı yoḳdur, zīrā her kişiye gereklüdür. Cerrāh olan kimsenüñ avadanlıg்ı uz ve arı gerekdür, şöyle kim altun yā gümiş yāhūuz kal'aylı ola kim andan yaraya żarar olmaya. (A.C. 4a-b)" . Bu ifadelerden anlaşılacağ 1 üzere cerrahlık ilim ile amel edilen bir iştir, her insan için gereklidir ve cerrah olan kişinin kullandığı cerrahî aletler kullanışlı ve temiz olmalı; altın, gümüş veya kalay gibi belirli cevherlerden yapılmalıdır.

\section{INNCELEME}

Yukarıda isim ve nüsha bilgilerini verdiğimiz eserlerde geçen cerrahî aletler, dağlama aletleri, delici aletler, kesici aletler ve diğer cerrahî el aletleri olmak üzere dört kavramsal başlikta verilmiştir. Bu sıralamada aletin geçtiği eserler kısaltılarak varak ve satır numarası ile açıklanmış ve bazı alet adlarında metinden örnekler seçilmiştir.

\section{Dağlama Aletleri:}

'adesī (ara) Bir tür dağlama aletidir. Sabuncuoğlu aletin çizimini vermiştir. Eger zāc-1la ḳab munkațı' olmazsa daǵlayasın, şol daǵlag̉u-y-1la kim 'adesī diyü žikr itmişüz, șūreti budur (C.H. 75b/15).

dağlaġı/ daġlaġu Daglama aleti. Sabuncuoğlu'nun eseri hariç diğer eserlerde belli bir dağlama aletinden söz edilmemektedir. Sabuncuoğlunda ise farklı boyutlarda kullanılan her biri farklı bir şekilde adlandırılmış dağlama aletleri vardır. Şol hūre kim burunda olsa yāhūu șolık yerinde olsa dag̀lag̉u hācet olmaz (H.T. 46b/15, 47a/3; C.H. 17b/9; A.C.79a/10, 79a/7, 79b/3).

dāyire dağlaġu Daire şeklinde bir dağlama aletidir. Sabuncuoğlu aletin çizimini vermiştir. Eger görseñ kim böyle olmışdur, dag̉layasın bir dāyire dag่lag்u-y-1la kim oñurganuñ dört yanı berāber daġlana (C.H. 43a/2, 47b/4).

demürcük Küçük demir. Metinden anlaşıldığı kadarıyla bir dağlama aletidir. Hakkında ayrıntılı bilgi ve çizim yoktur (H.T. 6a/9; A.C. 93a/10).

depesi yașș1 dağlag̉u Bir tür dağlama aletidir. Bkz. miḳvāt-1 mismārī.

giccük mikvāt Bir tür dağlama aletidir. Sabuncuoğlu aletin çizimini vermiştir. Eger ziyāde dāg itmege muḥtāc olursa dāg idesin, iki gözün kuyrugìndan yaña bir giccük mikvāt-1la iki gözinüñ kuyruginda (C.H. 24a/9).

hilāli daġlag̉u Ucu ay şeklinde olan bir dağlama aletidir. Sabuncuoğlu bu cerrahî aletin çizimini de vermiştir: Eger bu 'amelde kan boşanursa dāg idesin hilālī dağlağu-y-1la, șūreti budur kim görürsin. Bu daǵlagu şol dag̉lag̉udan kim bezler yirinde olan 'illetlerüñ kim ḳanı boşansa ya çürük eti olsa isti ' māl olınur (C.H. 96a/12).

miḳvāt-1 mismārī Bir tür dağlama aletidir. Sabuncuoğlu aletin çizimini vermiştir. $Y^{\prime} n \bar{i}$ şol depesi yașș1 dağlagiu kim depesi mịh depesi gibidür (C.H. 18a/16).

mikvāt-1 'adesī Bir tür dağlama aletidir. Sabuncuoğlu aletin çizimini vermiştir. Eger ḳanı diñmese dāg urasın, şol dag̉lag̉u-y-1la kim ețıbāa aña mikvāt-1 'adesi dirler(C.H. 60a/3). 


\section{F.Ü. Sosyal Bilimler Dergisi 2015-25/1}

mismārī țag̉lagiu Çiviye benzeyen bir tür dağlama aletidir. Sabuncuoğlu aletin çizimini vermiştir. (C.H. 24b/3, 35b/10, 36b/4).

müselles dag̉lağu Bir tür dağlama aletidir. Sabuncuoğlu aletin çizimini vermiştir.

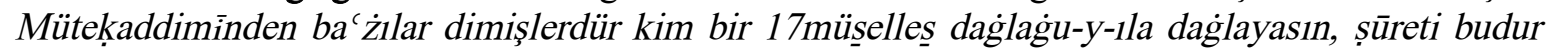
(C.H. 44b/17).

nokța (ara) Bkz. noḳta dag̉lag̉u. Şol mikvāt-1la kim ețbbā aña noḳta diyü ad virmişlerdür. (C.H. 30b/1, 31b/15).

noḳta daġlagiu Bir dağlama aletidir. Ve eger od-1la dāg urmak dileseñ, uvak noḳta daǵlaǵu-y-1la çok yirde depesine dāg urasın (C.H. 23a/14, 42b/7).

țag̉laġu Dağlama için kullanılan aletlerin genel adı. Kişi anda ḥāżır ola, oda țag̀laǵu ḳoya, kelbeten ile ol ocakdag்ı demür ḥāżır ola (A.C. 6a/11, 69a/7).

üç budaḳlu dag̉laġu Bir dağlama aletidir. Sabuncuoğlu aletin çizimini vermiştir (C.H. 30b/3).

zātü's-sikkīneyn İki uçlu dağlama aletidir. Şol mikvāt-1la ya'nī şol dag̉lag̉u-y-1la kim eṭbbā ol

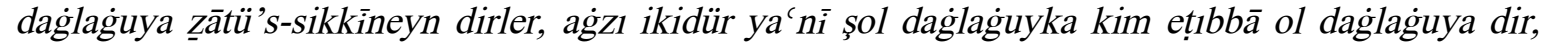
aǵz1 ikidür (C.H. 19b/8).

zeytūnī (ara) Bir tür dağlama aletidir. Sabuncuoğlu aletin çizimini vermiştir. Andan șoñra başın yülidesin 'alīlüñ, bir dāg urasın başınuñ ortasında, şol dag̉lag̉u-y-1la kim aña zeytūní dirler (C.H. 24b/3, 35a/3, 39a/12).

\section{Delici Aletler:}

cerrāḥ matḳābı Delici alet, matkap (H.T. 29a/10).

delecek ālet Anonim Cerrahname'de baş yarıklarında kullanılan bir alettir. Alet hakkında detaylı bilgi yoktur, aletin çizimi de bulunmamaktadır. Eger kemük rakik olursa keseler ve eger galīz olursa kemügüñ ețrāfinı deleler, ammā huažer ideler ki delecek āleti ġıșāya yetişmeye (CA. $125 \mathrm{a} / 8)$.

düdük Kalaydan yapılma ucu huni şeklinde sivri bir alettir. Metinden anlaşıldığ kadarıyla anüsü kapalı olarak doğan erkek çocuklarının anüsünü delmek için bu alet kullanılmaktadır. Çizimi bulunmamaktadır. Bir dahıı aǵzına düdük șoḳalar, șu aḳıdalar, ol, șuyı görmeye (CA. 152a/9).

igne İ̆gne. Genel olarak delici olarak kullanılan bir cerrahî alettir. yara içine șaçalar, andan dikeler ol igne-y-ile kim dikeler, ince ola ve uzun ola (A.C. 7a/6, 13a/10; CA. 85a/7; H.T. 6b/10).

kıı‘ (ara) Kalaydan yapılan sivri, delici bir alettir. Sabuncuoğlu yapılışını ve çizimini ayrıntılı olarak göstermiştir. Nāșūrı yaralar, yardukları yire bir ucı ince kıı'` șoḳalar. Ve ol yarduḳları yirüñ çevresine hamì șıvayalar. Sūret-i ḳım` budur, bu k̦ım‘a bir dirhem miḳdārı erimiş kal' ay aḳıdalar ve kım's berk țutalar (C.H. 27a/6).

masra/ masura (gre) Üzerine iplik, şerit, fitil gibi şeyler sarılan koni yahut silindir şeklindeki parça (A.C. 200a/2, 269a/2).

matkāa (ara) Tahta ve maden benzeri nesnelere delik açmaya yarayan yay (A.C. 16a/10; H.T. $29 \mathrm{a} / 11)$.

mișkab (ara) Delici alet, matkap. Büyük orta ve küçük olmak üzere üç türü bulunan bu kesici aletin çizimlerini Sabuncuoğlu eserinde göstermiştir. Pes gerekdür kim nāṣūruñ etin gideresin devāyı hădd-ile yāhūd demür-ile, tā kim kemük açıla, andan șoñra alasın bir miškab kim șūreti budur (C.H. 174a/3; (C.H. 66a/9).

mıḥkan (ara) Şırınga. Metinden anlaşıldığı kadarıyla deride oluşan irini temizlemede kullanılan bir aletdir. Eger maḩbānuñ aġzı țar olursa kim mıḥkan lülesi girmese, ālet-ile gigdiresin yāhūū bir fetīle düzesin (C.H. 140b/5, C.H. 99b/14). 
mıș aṭ (ara) Toz halindeki ilacı buruna üfürmek için kullanılan cerrahî alettir. Sabuncuoğlu eserinde çizimlerini göstermiştir. Eger kuruducı mu'āleceye muhtāe olursa, otları işbu mıṣ'aț-1la buruna üfüresin, șūreti budur ki gördüñ (C.H. 70b/7).

mil (ara) İnce uzun metal çubuk (A.C. 28b/2, 37b/3).

ünbūbe (ara) İnce boru. Andan șoñra ünbūbeyi dişüñ üzerine ḳoyup ve ol daǵlaǵuyı ḳıdurup ol ünbūbenüñ içine șoḳasın (C.H. 28b/11, 49a/11).

zerrāḳa (ara) Baş bölgesindeki cerrahî uygulamada kullanılan bir alettir. Sabuncuoğlu yapılışını ve çizimini vermiştir. İşbu ālet-ile kim idesin kim eṭıbā bu ālete zerrāka dirler, șıfatı budur ki görürsin. İçerü giren ucı mușmet ya' nī bitevī ola, ammā delügi ola, iki delügi bir yanında ola, bir delügi yanında ola (C.H. 99a/10).

\section{Kesici aletler:}

berīd (fas) Metin içi çeviriden anlaşıldığı kadarıyla kan almada kullanılan bir hacamat aletidir. Sabuncuoğlu bu aletin çizimini vermiştir. Eger mīl göze āsānlıg-1la girmezse gözüñ katılig 1 sebebinden, zīrā ki ba' żı kişilerüñ gözi katı olur. Eger göz katı olursa bir mibża' alasın kim aña berīd dirler (C.H. 69a/2).

bıçak Bıçak. Yaygın bir şekilde kullanılan cerrahî alettir. Bütün dönem metinlerinde geçmektedir. Yerinde saç kalursa bıçak uc1-y-1la çekeler, anuñ gibi ḳıluñ dibi yoġun olur, kan çıkmaz, bir dahı vuralar. (A.C. 81a/9; CA.148a/8; C.H. 131b/16).

bıçḳu Dişli bir kesici alettir. Alet hakkında ayrıntılı bilgi verilmemiştir. Metinden anlaşıldığı kadarıyla kemik kesmede kullanılan bir alettir. Ve bir șınıfi ancılayındur kim iki bıçkunuñ dişleri birbirine gire (A.C. 126a/10).

demür/ demir Madenden yapılan kesici bir alettir.Neşter olarak adlandırılabilir. Kan alsalar büyük açmayalar ve üzerine mercümek gibi țag uralar demürle (CA. 43a/4; H.T. 59a/14).

destere Testere. Kemik kesmekte kullanılan bir alettir. Ve eger kemük müteekkil olmış olursa etlerin ayıralar dahı destere ile kemügi keseler (CA. 114b/3; H.T. 6b/4).

diken uçlı nişter Bir tür neşter. Bkz. mibża' -1 şevḳi

dörpi Törpü. Metinde diş ve kemiklerde bu alet kullanılmaktadır: Diş uzansa ne vech-ile 'ilāc olınur, anı beyān ider. Gerekdür ki keseler yā dörpülüyeler (CA. 38b/10).

fe's (ara) Sözlüklerde "iki yüzlü balta" olarak verilmiştir. Metin içi çeviriden anlaşıldığ 1 kadarıyla balta şeklindeki neşterdir. Sabuncuoğlu aletin çizimini vermiştir. Anuñ fașdınuñ keyfiyyet-i 'ameli oldur kim 'alīüñ 'imāme pāresi-y-ile bog̀uzın bog̀asın, andan șoñra şol āleti alasin ol ālete fe's dirler, șūreti budur (C.H. 153a/1).

hıcāmat āleti Neşter. Bkz. mişrat.

ige Kesici bir alettir. Sabuncuoğlu bu cerrahî aletin çizimini de vermiştir: Eger ol diş bek-ise ve yiri muḥkem-ise igelemege țurış virürse, bir eyü pūlāddan düzülmişs ige alasın, ol ige-y-ile kesesin, igenüñ șūreti budur kim görürsin (C.H. 74b/8).

ince agızlu mıkța‘ Kemiği kesmek için kullanılan bir alettir. Sabuncuoğlu bu cerrahî aletin çizimini de vermiştir: Ammā kemügüñ kesip çıḳarmaġuñ iki vech üzerinedür: Birisi oldur kim kemügi bir lațī ince aǵızlu mıḳta'-1la kesesin kim șūreti budur göresin (C.H. 173b/5).

irende Rende. Ayırtlanmamış ola, aña matkāa gerekdür ve kimisine oḳ irendesi gerekdür (A.C. 23a/2).

kasāâțiir (ara) Hastanın anüs bölgesi için hazırlanan nasıl yapıldığının ayrıntılı anlatıldığı ve çiziminin de gösterildiği bir alettir. Kavuḳuñ içine vara, 'alīl derḥâl işeye. Eger bu didügümüz 


\section{F.Ü. Sosyal Bilimler Dergisi 2015-25/1}

'amel-ile halāṣ bulmasa 'alīiüñ zahmeti artsa, alasın şol āleti kim aña ețibbā ḳasātīir dirler, șūreti budur kim görürsin (C.H. 98b/3).

kazagi Kazımakta veya temizlemekte kullanılan alet olmakla beraber alet hakkında ayrıntılı bir bilgi yoktur. Dönem metinlerinden sadece Alāim-i Cerrāhịin'de geçmektedir. Eger kemükde çürük et yā iriñ hațā itmedi-y-ise kazag̉uy-1la arıdalar (A.C. 105a/10).

kazıyacak ālet Kazıma ve temizlemede kullanılan bir alettir. Sabuncuoğlu ayrıntılı bilgi vermiş ve çizimini de göstermiştir. Bkz. micred. Ya'ni kazıyacak ālet bu micredüñ başı mïh başı gibi ola degir nakșı ige nakșsı gibi ola, mafșıllar başı ya büyük kemüklerde ya yașșı kemüklerde fesād olsa 'ilāc idesin (C.H. 138a/3).

kemük kesecek ālet Kemik kesmede kullanılan bir alettir. Sabuncuoğlu alet hakkında ayrıntılı bilgi vermiş ve çizimini göstermiştir. Bak. mıkāt Ve eger ol ufak kemük yirinden aynılmış ve tamām kopmamış olursa anı hịle-y-ile kesmek ardınca olasın, yukaruda beyān idüp gösterdügümüz mıkāț dan ya'nī kemük kesecek āletlerüñ biri-y-ile (C.H. 178a/14).

levleb (?) Kadın genital hastalıklarında uygulanacak cerrahî operasyonda kullanılan bir alettir. Sabuncuoğlu aletin çizimini de vermiştir: Bu ālete ețbbā levleb dirler, miftāḥu'l-ferc dah̆ı dirler (C.H. 113a/8).

maḳādih (ara.) Göz bölgesine uygulanan cerrahî operasyonlarda kullanılan bir alettir. Sabuncuoğlu aletin çizimlerini göstermiştir. Șūret-i makāạh bunlardur: Bu miḳdaḥlan nuḥāsdan düzesin, ucu dahı ve sivriligi dahı böyle gerekdür kim göresin (C.H. 69b/8).

mesābir (ara) Sözlüklerde yara sarmada kullanılan fitil olarak tarif edilmiştir. Metinden anlaşıldığı kadarıyla büyük, orta ve küçük olmak üzere üç türü bulunan, kesme ve yarmada kullanılan bir cerrahî alettir. Sabuncuoğlu çizimlerini vermiştir. Bir dürlü ālet dahı̆ kim aña mesābir dirler, berīd dahı dirler, bu dah̆ı üç nev'dür (C.H. 87a/9).

mıḳăt (ara) Kemik kesmede kullanılan bir alettir. Metin içi çeviriden kemik kesme aleti olduğu anlaşılmaktadır. Sabuncuoğlu aletin çizimlerini de göstermiştir. Ve eger ol ufak kemük yirinden ayrılmış ve tamām kopmamış olursa anı hỉle-y-ile kesmek ardınca olasın, yukaruda beyān idüp gösterdügümüz mıkāțtan ya'ni kemük kesecek āletlerüñ biri-y-ile. (C.H. 178a/13).

mibża' (ara) Sözlüklerde kan alma aleti olarak tarif edilmiştir. Metin içi çeviriden anlaşıldığı kadarıla, iki tarafı da keskin neşterdir. Sabuncuoğlu aletin çizimini göstermiştir. Andan șoñra bir mibza' ya'nī nişster alasın kim iki țarafi bile tīz ola, șūreti budur ki göresin (C.H. 55b/6; 58a/2, $73 b / 1)$.

mibża' -1 neşli Bir neşter türü. Sabuncuoğlu çizimini göstermiştir. kim ol mibża`a ețıbā mibża'-1 neşli dirler, șūreti budur kim görürsin (C.H. 101a/4).

mibża ${ }^{-}-1$ sikkīni Bir tarafı keskin ve bir tarafı keskin olmayan neşterdir. Sabuncuoğu çizimini göstermiştir şol āleti alasın kim aña mibżac -1 sikkinin dirler, bir țarafi keser ve bir țarafi tīz degüldür (C.H. 55b/11; 152a/17).

mibża' -1 şevḳ̄i Ucu sivri olan bir neşter. Sabuncuoğu çizimini göstermiş̧tir. İki barmaġınuñ arasına bir mibża'-1 şevkī ya'nī bir diken uçlu nişster ala, og̉lanuñ başını yara, (C.H. 117a/15).

micred (ara) Sözlüklerde diş temizlemede kullanılan dişçi aleti olarak tarif edilmiştir. Metin içi çeviriden anlaşıldığ kadarıyla bir tarafi keskin kazıma aletidir. bir ince lațîf ālet-ile kim be-gāàet yiti ola, ol ālete ețibbā micred dirler, arḳunlıg-1la kazıyasın (C.H. 70a/4,73a/1). 138a).

micred-i mu' aḳkaf Bir tür kazıma aletidir. Sabuncuoğlu bu aletin çizimlerini vermiştir (C.H.

micred-i mücevvef Bir tür kazıma aletidir. Sabuncuoğlu bu aletin çizimlerini vermiştir (C.H. 138a). 
micred-i mücevvef-i lațîf Bir tür kazıma aletidir. Sabuncuoğlu bu aletin çizimlerini vermiştir (C.H. 138a).

mides (?) Baş bölgesindeki şişleri yarmada kullanılan bir kesici alettir. Sabuncuoğlu bu aletin çizimini vermiştir. Bu işde țarịk-i 'amel oldur kim şak idesin anı, şol ālet-ile kim aña ețbbā mides $\operatorname{dirler}$ (C.H. 82a/14 aletin çizimi 87/a).

midfa‘ (ara) Kürtajda kullanılan bir alettir. Sabuncuoğlu aletin çizimini vermiştir. Ammā iş vaḳtında 'alīle bir çatal kürsī üzerine otura, şöyleki yitmiş dördünci fașılda gösterdük, şöyle ki gördüñ, fe'fhem. șūret-i midfa' ya'nī og̀lanı içerü yitecek ālet budur(C.H. 119a/6).

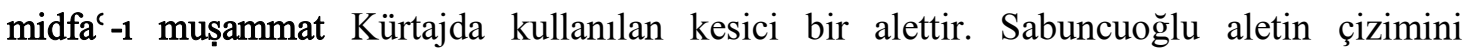
vermiş̧tir. Aña şol āleti șoḳasın kim aña midfa'-1 mușammat dirler ya'ní mücevvef degül bitevī dimekdür(C.H. 151a/1).

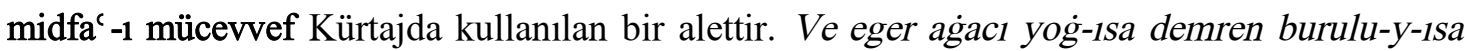
aña bir ālet șoḳasın, tā kim ol ālete ețbbā midfa'-1 mücevvef dirler. Bu āletüñ içi mücevvefdür, oḳuñ borusinı ol āletüñ mücevvef yirine șokasın, demreni ilerü yitesin (C.H. 150b/15). levleb

miftāhü'l-ferc (ara) Kürtajda kullanılan bir alettir. Sabuncuolu aletin çizimini vermiştir. $B k z$.

miḥceme (ara) Sözlüklerde kan almaya yarayan hacamat şişesi olarak tarif edilmiştir. Şoñra bir berk biz-ile muḥkem bagglayasın ve andan șoñra yine ol żikr itdügümüz yirden miḥceme urup sorasin (C.H. 67a/2).

miḳaș (ara) Makas. Genel bir alet adıdır. Sabuncuoğlu farklı vakalar için farklı makas çeşitleri belirtmiş ve çizimlerini göstermiştir. Sigili mibża'-1la ya mikaș-1la dibinden kesesin, andan șoñra saḥk olmış zācı ḳoyasın (C.H. 58a/13).

mik̦ta` (ara) Bir tür kesici alettir. Sabuncuoğlu aletin çizimini vermiştir (C.H. 138a).

mişdāh (ara) Bir tür kesici alettir. Sabuncuoğlu aletin çizimini vermiştir. Ve eger og̉lanuñ başı büyükligi sebebinden olursa og̉lanuñ başını tọgrayalar, şol ālet-ile kim eṭıbbā ol ālete mişdāh dirler (C.H. 117a/17).

mişrat (ara) Neşter. Hicāmatı gevde țamarından ḳan almak gibidür ve ammā mişrat ya'ni ḥıcāmat āletini deriñ șancmayasın (C.H. 161b/16; 162a/9; 87b/4).

neşli (ara) Bir tür neşter (C.H. 54a/12; 53b/7).

neşter (fas) Cerrahların kesmek ve yarmak için kullandıklanı ufak bıçak. Eger açılmazsa neşter-ile azacuk deleler ve çok aḳıtmayalar (A.C. 83b/7; H.T. 7b/3; (H.T. 50b/3).

nişster (ara)Neşter. Eger yumşamış ve yufkalmış olursa raḥmüñ başı ḳatından bir inlü nişster-ile dele, tā kim iriñi tamām çıka (C.H. 113b/5; C.H. 59a/14).

niş̧er-i reyḥānī Ana damarlar üzerinde kullanılan bir neşterdir. Sabuncuoğlu bu neşterin çizimini vermiştir. $\mathrm{Bu}$ nişster-i reyhānni inlürek gerek şöyleki göresin, bu nişster şol țamarlara muvāfiḳdur kim ol țamar yog̉un ve āşkārā ola ve țolu ve mücevvef ola (C.H. 154b/1).

oġlanı içerü yitecek ālet Kürtajda kullanılan bir alettir. Bkz. midfac

șanānīr-i 'umyān Uçları çok keskin olmayan bir kesici alettir. Sabuncuoğlu aletin çizimini vermiştir. Ve ba' żısına șanānīr-i 'umyān dirler ya'ní uçlanı tìz degüldür, bu dah̆ı üç nev'dür (C.H. $87 \mathrm{~b} / 8)$.

șanārīir'l-müzevvece Uçları çengelli olan bir kesici alettir. Küçük, orta ve büyük olmak üzere üç türü bulunur. Sabuncuoğlu aletin çizimini vermiştir. Ve ba'żısına șanāniri' 'l-müzevvece dirler, ol dahı ü̧̈ nev'dür: Uludur, ortadur, gicidür. Bu șanānīrüñ çengelleri ikişerdür, șūretleri bunlardur (C.H. 87b/2). 


\section{F.Ü. Sosyal Bilimler Dergisi 2015-25/1}

șındu Makas. Bkz. miḳaș (A.C. 85b/11).

sikkīnī Bir tür neşter (C.H. 20b/15, 24a/7, 27b/5).

sikkīnī nişsteri Bir tür neşter. Sabuncuoğlu aletin çizimini vermiştir (C.H. 154a/17).

sünnet kılıcı Sünnette kullanılan bir kesici alet (H.T. 5b/7).

ustura Ustura. Ve ba'żılar dimişler ki mevi̇ı`‘ ustura ile yaralar, çıkaracagıın çıkaralar yine münāsib 'ilāc ideler (CA. 122b/11).

\section{Diğer Cerrahî El Aletleri:}

başı mücevvef ālet Alet tanımlanmamış, hakkında bilgi verilmemiştir. Metinden anlaşıldığı kadarılla vücuda saplanan okları çıkarmakta kullanılmaktadır. Çizimi de eserlerde yer almamaktadır. Başı mücevvef ālet-ile eger oḳun ețāfinda zā’idleri olsa eger mümkin olursa kelbeteynile dört yanından eti bile dutalar ki āsānlı́g-1la çıka (CA. 101b/9).

bavāsīr dutacak ālet Alet tanımlanmamış, hakkında bilgi verilmemiştir. Metinden anlaşıldığı kadarıla boğaza giren sülüğü çıkartmak için kullanılan alettir. Çizimi de eserlerde yer almamaktadır. Eger yakıın olursa güneşe k̦arşu oturalar, dilini mīl-ile bașalar, bu bavāsir dutacak ālet ile aǵzına yaḳın çekeler (CA.41b/6).

bayram Bu cerrahî aletin çizimini Sabuncuoğlu eserinde vermiştir. Metinde irinli kırıklarda bu aletin kullanıldığı anlaşılmaktadır. Ayrıca Sabuncuoğlu "bayram" kelimesinin Yunanca olduğunu belirtmektedir. Bugün Türkçede kullandığımız bayram Farsça bezm+ram şeklinden gelmektedir. $\mathrm{Bu}$ kelimenin Yunanca bir tıp aleti olduğu Yunanca bir kaynaktan teyit edilememiştir. $B u$ ālete Yunan lugatında bayram dirler, bu āletüñ ucını kemüge direyüp kemügi yitesin, tā kim kemük içerü gide (C.H. m180/a 10).

berdī (per) Osmanlıca sözlüklerde berdī kelimesi Farsça bir bitki adı olarak geçmektedir. Kulağa giren nesneleri çıkarmak için kullanılan bir alettir. Metinden anlaşıldığına göre kamıştan yapılmaktadır: Ve bir dürlü 'amel dahı budur kim berdì alasın, berdì bir kamıșdur kim Mıșır'da, andan kāgid düzerler, palāndūz kamışı aña bedeldür. Ol ḳamışuñ bir ucını 'alïlüñ ḳulagina șoḳasın (C.H. 58a/12).

bir delükli ḳısac/ bir delüklü ḳısac Bir deliği olan kerpeten (H.T. 8b/15; A.C. 69b/1).

çengāl (fas) Çengel. Şeftālū yapraġın dögeler, șuyın alalar, țamzuralar, öldüre, gidere, çifte-yile yā çengāl-ile çekeler (A.C. 85a/7; C.H. 54a/13).

çift (fas) Küçük maşa veya cımbız. Kulağa giren nesnelerden parçalanmış kemiklere kadar geniş bir alanda bu alet kullanılmaktadır. Kopmış kemigi var-ısa çıkarasın uzluǵ-1la ve çift-ile anuñ çiftesi sivri gerekmez (A.C. 23b/10; C.H. 57a/12).

demür çengel Eğri ve ucu sivri demir (H.T. 75a/10).

demür halaḳa Demir halka. Metinden anlaşıldığı kadarıyla siyatik hastalığı için hazırlanan bir alettir. Ammā şol dāg kim devā-yı muhrik-iledür, anuñ țarịk-i 'ameli oldur kim bir demür halaḳa düzesin, kapu ökçesine geçen ḥalaḳa gibi, baḳırdan yāhūd demürden (C.H. 39a/10).

iki delükli ḳısac/ iki delüklü ḳısac İki tarafı delikli kerpetendir. Aletin çizimi verilmemiştir (H.T. 8b/15; A.C. 69b/1).

kelbetān/ kelbeten/ kelbeteyn/ kelbetün (ara kelbetān) Kerpeten. Dönem metinlerinde en çok geçen aletlerden biridir (C.H. 73b/2; CA. 101b/6; H.T. 6b/4, 50a/11; A.C. 69a/7, 93a/10).

ḳısaç Kıskaç, kerpeten. Ol demür-ile delesin, ipligi geçüresin, andan ḳısacı gideresin andan igneyi girü ol delükden dönderesin. (A.C. 69a/9, 69b/1). 
kulaḳ arıdacak ālet: Alet hakkında ayrıntılı bilgi verilmemiştir. Metinden anlaşıldığı kadar kulağa giren nesneleri temizlemede kullanılan bir alettir. Kulaǵa țamzuralar, bir gün koyalar, andan güneşe ḳarşu dutalar, kulaḳ arıdacak ālet-ile arıdalar (CA. 9b/11).

mengene (gre) Nesneyi sıkıştırıp istenildiği gibi tutturmaya yarayan bir çeşit alet (A.C. 57a/2, 57b/1; H.T. 23b/9)

mibhar (?) Ağız hastalıklarında kullanılan bir alettir. Sabuncuoğlu aletin çizimini göstermiştir. Bir ālet düzesin gümişden ya baḳırdan, āletüñ șūreti budur kim görürsin, bu ālete dahı mibhar dirler, bu ālet müdevver ola (C.H. 79a/12).

minkāş (ara) Cımbız. Ve eger verem giccük olursa bir minḳāş-1la veremi țutasın, dibinden kesesin (C.H. 91a/1; CA. 125a/11).

safiḥa (ara) Metalden yapılma ince levhac1k. Eger kemük 'użv-1 şerīfüñ üzerinde olursa eyegi gibi meșelā ġışā'-1 müstabțin arasına bir șaḥiffa ḳoyalar (CA. 114b/5).

șinnāre (fas) Çengel şeklinde bir alettir. Andan șoñra șınnāre-y-ile ya'nī çengāal-ile şiryānı yuḳaru ḳaldurasıni çekesin, çıkarasın, șıfâkdan ḳurtarasın (C.H. 54a/13, 57a/13).

șınnāre-i 'amyā Bir ucu eğri ve bir ucu kısa olan cerrahî alettir. Sabuncuoğlu aletin çizimini vermiş̧ir. Eger çift-ile çıkmazsa alasın bir șınnāreyi kim be-ḡāyet ince ola ve egrisi az ola ve ucı künd ola, aña șinnāre-i 'amyā dirler, șūreti budur (C.H. 57a/14).

til Kalaydan yapılan ince tel. Eger göresin kim 'alīl demür-ile kesmekden korkarsa, alasin bir kal' ay țil kim ince ola iplik gibi, sigili anuñ-1la berk bag̀layasın, șūreti budur(C.H. 91b/1).

țamzuracak Damlalık. Kulag̉uñ içresinde mütemekkin olmış ola, ḳulaḳ șaǵır olduġı vaḳt z̧ikr itdügümüz yaǵları ki țamzuracaḳları ile 'ilāc ideler (CA. 6b/9).

üç delükli ḳısac/ üç delüklü ḳısac Üç deliği olan kerpeten (H.T. 8b/15; A.C. 69b/1).

yassılama Tırnakta oluşan yaralanmalara karşı kullanılan bir düzeltme aletidir. Aletin çizimi bulunmamaktadır. Ve bir nev'i țırnak șaru olmakdur, 'ilācı bezr-i cırcır ile ve sirke ile żamād ideler. Ve bir nev'i yașșilama ile yașșllanmadur (CA. 148b/9).

\section{SONUÇ}

Çalışmamızda Osmanlı cerrahî tıp yazmalarında karşılaştığımız yüz üç cerrahî alet adını sözlük düzeniyle verdik. Örneklerini aldığımız dört cerrahî tıp kitabı arasında en çok cerrahî alet adı Sabuncuoğlu Şerafeddin'in Cerrahiyetü'l-Hâniye adlı eserinde geçmektedir. Ancak Sabuncuoğlu'nun eserinini biraz da çeviriye dayanıyor olması sebebiyle Arapça ve Farsça terimler Türkçe terimlerden daha fazladır. Yine Sabuncuoğlu eserinde yaklaşık yüz altmış sekiz cerrahî aleti şekliyle tarif etmiştir. Ancak bunların bazılarına herhangi bir isim vermemiş (Bkz. 34a, 42a, 43a 174b numaralı varaklar), bazılarında da değişik ifadeler kullanmıştır: $B u$ ālet Yunanīlerin 'aynına benzer (105a), bu ālet Yunanīlerüñ lāmı șūretindedür (63a) gibi. İncelediğimiz diğer cerrahî metinlerde aletler sadece adlandırılmış, ancak aletin nasıl yapıldığı tarif edilmemiş̧, çizimi verilmemiştir. Ayrıca, cerrahî aletlerin Sabuncuoğlu'nun eserindekilere göre daha basit olduğunu söyleyebiliriz.

Bıçak, bıçḳu, düdük, demürcük, kazag̉u, kısaç, șındu, țamzuracak, til, yașṣılama gibi tek sözcükten oluşan Türkçe alet adları ile kemük delecek ālet, başı mücevvef ālet, bavāsir dutacak ālet, depesi yașșı dag̉lag̉u, diken uçlı nişster, iki delükli kısac/ iki delüklü ḳısac, kazıyacak ālet, og̀lanı içerü yitecek ālet, üç budaḳlu dag̉lag̉u gibi genellikle sıfat tamlaması şeklinde kurulmuş olan alet adları dikkat çekicidir. Bazı alet adlarında ise metin içi çeviri yapılarak Türkçesi verilmeye çalışılmıştır.

Cerrahî alet adlarına köken olarak baktığımızda yirmi yedi sözcüğün Arapça kökenli, yedi sözcüğün Farsça, üç sözcüğun ise Yunanca kökenli olduğunu görmekteyiz. Kullanılan yabanc1 


\title{
F.Ü. Sosyal Bilimler Dergisi 2015-25/1
}

kökenli sözcüklerin çokluğu eserin tıp metni olması sebebiyle o dönemde tıp literatüründe Arapça, Farsça ve Yunancanın etkili olmasına bağlanabilir. Tek sözcükten ibaret Türkçe cerrahî alet adlarının sayısı yirmi bir iken bir sözcük grubu olarak karşımıza çıkan alet adları ise yirmi dörttür. Sözcük grubu şeklinde olan aletlerde ise genellikle alet işlevi adlandırmaya temel oluşturmaktadır: Bavāsir dutacak ālet,delecek alet, kemük delecek ālet, kazıyacak ālet, kulak arıdacak ālet, og̀lanı içerü yitecek ālet gibi. Ayrıca Farsça usulle yapılan sözcük gruplarının Arapça usulle yapılanlardan daha fazla olduğunu görülmektedir.

\author{
Kisaltmalar \\ ara Arapça \\ fas Farsça \\ gre Yunanca \\ otk Türkçe (1500'e kadar) \\ ota Türkçe (1500-1928)
}

C.H. Cerrahiyetü'l-Hâniye (Paris Bibliotheque National Turc 693)

C.H. m. Cerrahiyetü'l-Hâniye (Fatih Millet Kütüphanesi 79)

A.C. Alâim-i Cerrâhin (Süleymaniye Kütüphanesi Hekimoğlu Ali Paşa 568)

H.T. Hülâsa-i Tib ( Süleymaniye Kütüphanesi 3550)

CA. Anonim Cerrahnâme (İstanbul Arkeoloji Müzesi Küt. 729.)

\section{KAYNAKÇA}

ACIDUMAN, Ahmet- Uygur Er- Deniz Belen (2008), Geç Osmanlı Dönem Eserlerinden Bursalı Ali Münşi'nin Cerrahnamesinde Nöroşirürji, Türk Nöroşirürji Dergisi, cilt 18, say1 1, s.5-15.

Alâim-i Cerrâhîn, Süleymaniye Yazma Eserler Kütüphanesi, Hekimoğlu Ali Paşa 568.

Anonim Cerrahname, İstanbul Arkeoloji Müzesi Küt. 729.

AYVERDİ, İlhan (2005), Misalli Büyük Türkçe Sözlük, Kubbealtı Neşriyat, c. 3, İstanbul.

BAYRAM, Mikail (1995), Anadoluda Telif Edilen İlk Türkçe Eser Meselesi, V. Milli Selçuklu Kültür ve Medeniyet Semineri Bildirileri (25 -26 Nisan 1995), Konya, s.95-100.

Burhân-ı Katı (2006), (Haz. M. Öztürk, D. Örs), TDK Yayınları, Ankara.

CANPOLAT, Mustafa (1973), XIV. Yüzyılda Yazılmış Değerli Bir Tıp Eseri, Türkoloji Dergisi,sayı 19 , s. 21-32. 19

Cerrâhiyyetü'l-Hâniyye, Paris Bibliotheque National Turc 693.

Cerrâhiyyetü'l-Hâniyye, Fatih Millet Küt. 79

DEVELLİĞLU, Ferit (2005), Osmanlıca- Türkçe Lûgat, Aydın Yayınları, Ankara.

DİLÇiN, Cem (1983), Yeni Tarama Sözlüğ̈̈, TDK Yayınları, Ankara.

GÜRLEK, Mehmet (2011), İbrahim bin Abdullah'ın Alâim-i Cerrâhîn Adlı Eseri (Giriş-Metin-Sözlük), Marmara Üniversitesi Sosyal Bilimler Enstitüsü, Yayımlanmamış Doktora Tezi, İstanbul.

Hâzâ Kitâb-ı Hulâsa-i Tıbb, Süleymaniye Yazma Eserler Kütüphanesi, No. 3550.

İslâm Ansiklopedisi, TDV Yayınları, 7. cilt, s. 423-425. İstanbul.

İZGİ, Cevat (1997), Osmanlı Medreselerinde İlim, 2 cilt, İstanbul İz Yayınc1lı.

KAHYA, Esin (2013), Osmanlı İmparatorluğundaki Cerrahi Çalışmalarından Bazı Örnekler , http://turkoloji.cu.edu.tr/GENEL/26.php (23.02.2014 tarihinde ulaşıldı). 
KILIÇ, Abdullah (2012), Anadolu Selçuklu ve Osmanlı Şefkat Abideleri Şifahaneler, İstanbul.

MUALLİM, Naci (2000), Lugat-i Naci, Çağrı Yayınları, İstanbul.

SAMİ, Şemseddin (2005), Kamus-ı Türkî, Çağrı Yayınları, İstanbul.

UÇAR, İlhan (2009), Hazâ Kitâb-ı Hulâsa-i Tıbb Cerrâh Mes'ûd (Giriş-İnceleme- Metin-Dizinler, Sakarya Üniversitesi Sosyal Bilimler Enstitüsü Yayımlanmamış Doktora Tezi, Sakarya.

UZEL, İlter (1992), Sabuncuoglu Serefeddin, Cerrahiyyetü'l-Haniye I-II, Atatürk Kültür Merkezi Yayını, Ankara.

YAVUZ, Serdar (2013), Cerrah-name, Kesit Yayınları, İstanbul. 
